Detlef Gysau

\title{
Füllstoffe
}

\section{Grundlagen und Anwendungen}

3., überarbeitete Auflage 
Umschlagbild: (c) Africa Studio - Fotolia.com

Bibliographische Information der Deutschen Bibliothek

Die Deutsche Bibliothek verzeichnet diese Publikation in der Deutschen Nationalbibliographie; detaillierte bibliographische Daten sind im Internet über http://dnb.ddb.de abrufbar.

\section{Detlef Gysau}

Füllstoffe, 3., überarbeitete Auflage

Hannover: Vincentz Network, 2014

FARBE UND LACK // BIBLIOTHEK

ISBN 978-3-74860-016-9

\section{(C) 2014 Vincentz Network GmbH \& Co. KG, Hannover}

Vincentz Network, P.O. Box 6247, 30062 Hannover, Germany

Das Werk einschließlich seiner Einzelbeiträge aus Abbildungen ist urheberrechtlich geschützt. Jede Verwendung außerhalb der engen Grenzen des Urhebergesetzes ist ohne Zustimmung des Verlages unzulässig und strafbar.

Dies gilt insbesondere für die Vervielfältigungen, Übersetzungen, Mikroverfilmungen und die Einspeicherung und Verarbeitung in elektronischen Systemen.

Das Verlagsverzeichnis schickt Ihnen gern:

Vincentz Network, Plathnerstr. 4c, 30175 Hannover, Germany

Tel. +49 511 9910-033, Fax +49511 9910-029

E-mail: buecher@farbeundlack.de,www.farbeundlack.de

Satz: Heidrun Herschel, Wunstorf 
FARBE UND LACK // BIBLIOTHEK

Detlef Gysau

\section{Füllstoffe}

Grundlagen und Anwendungen

3., überarbeitete Auflage 
Für Jacqueline, Gian-Flurin und Mica-Ladina sowie Easy, Fuchur und Nellie

Keine Schuld ist dringender als die, Dank zu sagen.

Marcus Tullius Cicero

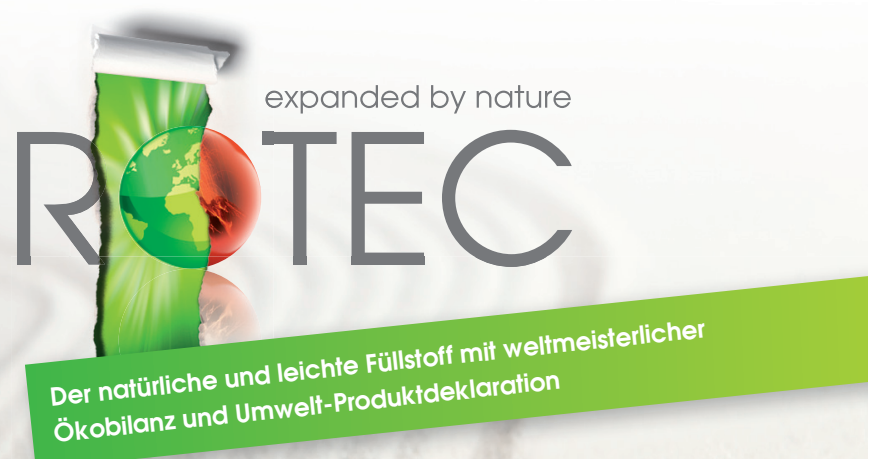

RQTOCELL \& RQTOBASE

verbesserte Nachhaltigkeit durch Reduktion der $\mathrm{CO}_{2}$-Bilanz

- rheologisch aktiv

puzzolanisch aktiv
- stabilisierend

- $100 \%$ natürlich

- $100 \%$ mineralisch

- $100 \%$ recyclingfähig

ROTEC GmbH \& Co. KG • 56218 Mülheim-Kärlich • Tel. +492630 96515-0 www.rotec-nature.com 